\title{
INVESTIGATING THE COOLING RATE OF CANE MOLASSES AS QUENCHING MEDIUM FOR 0.61\% C HIGH CARBON STEELS
}

\author{
M. R. Dodo ${ }^{1 *}$, T. Ause $^{1}$, E. T Dauda ${ }^{1}$, M. A. Adamu ${ }^{2}$ \\ ${ }^{1}$ Department of Metallurgical and Materials Engineering, Ahmadu Bello \\ University Zaria,Nigeria. \\ ${ }^{2}$ Department of Mechanical Engineering, Ahmadu Bello University \\ Zaria,Nigeria
}

Received 10.11.2015

Accepted 14.03.2016

\begin{abstract}
The effect of cooling rate of cane molasses as quenching medium for $0.61 \% \mathrm{C}$ high carbon steels was investigated. Samples of high carbon steel were spheroidized annealed and then machined prior to the hardening process. Molasses solution of viscosity equals to that of engine oil was prepared by adding water. The samples were normalized and then austenitised at $800^{\circ} \mathrm{C}$ and soaked for 40 minutes and then quenched in water, engine oil, raw molasses and the prepared molasses solution. Cooling rate curves of all the quenching media used were developed. The highest cooling rate of $60^{\circ} \mathrm{C} / \mathrm{s}$ was attained by the prepared molasses solution. Hardness of the test samples was evaluated. The test results obtained show that the highest hardness value (525 HVN) was obtained from the sample quenched in the prepared molasses solution. Microstructures of the various samples were analyzed using OM and SEM. In all the tests samples martensite structure was observed. It was observed that the prepared molasses solution has higher severity of quenching than that of engine oil but lower than that of water. The research showed that cane molasses can harden high carbon steel without cracking the component in the same way as engine oil, hence, molasses could be a very good alternative to engine oil for use as quenching medium.

Keywords: Martensite, Quenching, Cane Molasses, Viscosity, Cooling Rate, High Carbon Steels
\end{abstract}

\section{Introduction}

Steel is a very versatile engineering material with a wide range of attractive properties and a very competitive production cost. It has diverse range of applications

\footnotetext{
*Corresponding author: M. R. Dodo, ray.dodo@yahoo.com
} 
and is second only to concrete in its annual production tonnage [1]. The properties (usually mechanical properties) of steels which in most cases fit the service requirement are mostly, achieved by various kind of heat treatments operations [2]. Quenching, as one of the most important processes of heat treatment, can improve the performance of steel greatly, but an important side effect of it is the formation of thermal and transformational stresses that cause changes in size and shape and may result in cracks [3]. Quenching of steels involves the process of heating a steel component above upper critical temperature to austenitizing temperature and holding at this temperature for a specified soaking time followed by intense cooling in a suitable quench medium. Quenching prevents the formation of ferrite or pearlite and allows the formation of bainite or martensite [4].

A medium that is used for quenching is called a quenchant. The primary function of a liquid quenchant is to facilitate the hardening of steel by controlling heat transfer during quenching and also to minimize the formation of undesirable thermal and transformation stresses which may lead to increase in distortion and cracking [5].

The commonly used quenchants are water, oil, brine, and synthetic solutions (such as polymer solutions). Water though abundant and low in cost has a drawback of inducing crack or dimensional changes on the quenched component due to its high cooling rate. Polymer quenchants have no definite pattern/trend of property improvement with varying concentrations and they are also more expensive relative to water. Brine produces more quenching severity than water and it also corrodes the component and the equipment used for the quenching. Low alloy and carbon steels can be quenched in brine solution; however, the rapid cooling rate of brine can cause cracking or distortion in high carbon and low alloy steels [6].

Over the years, engine oil (machine oil) has been found to be suitable quenchant for high carbon steel [7]. When quenched in engine oil, high carbon steels could be hardened without cracking. However, two of the major problems associated with quenching in engine oil are; at times engine oil is combustible and could only be used under controlled atmospheres (either reducing or neutral) as the oxidation of the oil results in the formation of carboxylic acids and sludge which affects the induced hardness and colour of the work piece [8]. On the safety side, engine oil is hazardous to operate. Hence, there is need to develop a quenchant that is of low cost, environmentalfriendly, not corrosive, but effective in inducing the required hardness without the problems of distortion and residual stresses. Based on the above aforementioned reasons, this research focuses on the use of molasses as quenching medium for high carbon steels.

Molasses is a honey-like substance. It is a waste emanating from sugar processing [9]. In other words, it refers specifically to the final effluent obtained in the preparation of sucrose by repeated evaporation, crystallization and centrifugation of juices from sugar cane and sugar beets. Today, several types of molasses are recognized and in general, any liquid feed ingredient that contains in excess of $43 \%$ sugars is termed molasses [10].

Because of the problems of distortion, warping and high internal stresses associated with water quenching, researchers over the years have been searching for alternatives to water; using oil, oil emulsion and also polymer quenchants.

Balogun [11] worked on the possibility of using cassava extracts as a quenching media for plain carbon and low alloy steels. He concluded that cassava liquid extract 
could be used as a quenching medium which gives mechanical properties better than that given by SAE40 engine oil. Ause [12] studied hot bitumen bath as a quenching medium for austempering of steel and ductile cast iron. The finding shows that hot bitumen can be used as quenching medium in austempering process. Hassan et al. [13] also studied the hardening characteristics of plain carbon steel and ductile cast iron using Neem oil as a quenchant. It was revealed that neem oil could be used as a quenching medium. Muhammad [14] investigated the used of polymer (glycerol) quenchants for hardening process of steels and cast irons. It was found that aqueous solutions of polymer (glycerol) have quenching severity higher than that of oil but lower than that of water. Saska [15] studied the relationship between boiling rate, heat transfer and viscosity of cane molasses. The finding shows that thermal property (Heat Transfer Coefficient) of cane molasses is inversely proportional to its viscosity. Bodede et al. [16] evaluated as-quenched hardness of high carbon steels in different quenching media. It was reported that quenching in more severe media, such as water and brine, was found to result in adequate hardening.

\section{Materials and methods}

\section{Materials and equipment}

The materials used in this research work include: high carbon steel samples, cane molasses, water and SAE 40 Engine oil. The equipment used include: viscometer, copper calorimeter, balance, muffle furnace (electric resistance furnace), polishing machine, K-type thermocouple, optical metallurgical microscope (OM), scanning electron microscope (SEM), Vickers hardness tester and lathe machine.

\section{Methods}

Molasses solution with viscosity equal to that of engine oil was prepared by adding water. Viscometer was used to measure the respective viscosities of water, raw molasses, prepared molasses and SAE engine oil. Engine oil was used to serve as control. The machined samples were initially heated to $800^{\circ} \mathrm{C}$ and soaked for $75 \mathrm{~min}$ and then air-cooled; this was followed by austenitizing the samples to $800^{\circ} \mathrm{C}$, soaking for 40 minutes and then quenching in prepared molasses solution, raw molasses, water and SAE 40 engine oil. Half of the total number of the quenched samples was further tempered at $350^{\circ} \mathrm{C}$ for 40 minutes. All the quenching media were not agitated and maintained at room temperature of $27^{\circ} \mathrm{C}$.

\section{Hardness measurement}

Vickers hardness tester was used for hardness measurement. The hardness test samples were prepared to standard dimensions $(15 \pm 5 \mathrm{~mm})$. The test method adopted was ASTM E18. The samples were prepared with flat and smooth surface. A diamond indenter was used to indent the surface of the test specimen by the application of static load of 30kgf. Both diagonals of the impression were measured using a lower power graduated microscope. The mean value of the diagonal length was used in the determination of the hardness value.

The procedure was repeated at two different points on the test piece and the average was recorded. 


\section{Microstructural examinations}

All the specimens (both untreated and heat-treated) were prepared for optical microscopic examination. The specimens were ground on a water lubricated silicon carbide abrasive papers of 180, 240, 320, 400 and 600 grit sizes. Polishing was carried out on $15 \mathrm{~cm}$ rotating discs of a METASERV universal polishing machine with synthetic velvet polishing clothes impregnated with $1 \mu \mathrm{m}$ Alumina paste. The specimens were then etched with $2 \%$ Nital solution using the swabbing method with cotton wool soaked in the etchant.

The microscopic examinations were carried out on M100 optical metallurgical microscope and the microstructures obtained were captured within built camera.

SEM was also used for some of the quenched samples. The surface of the specimens to be examined was polished and then etched (as described above).

\section{Determination of cooling curve}

Cooling curves were obtained under unagitated conditions according to ASTM D6200-01 (the test method is based on the $12.5 \mathrm{~mm}$ diameter x $60 \mathrm{~mm}$ length of high carbon steel sample). A K-type thermocouple was fitted in a hole drilled at the geometric centre of the test piece. The test piece was heated in the furnace to $800^{\circ} \mathrm{C}$, held for 40 minutes, and then quenched in the prepared molasses solution. On cooling, the temperature dropped and the corresponding times were recorded. The data obtained were used to plot the cooling curve for the medium. The first derivative of the temperature with respect to time (cooling rate) was plotted against the corresponding time. The same procedure was repeated for the raw molasses, water and SAE engine oil.

\section{Results and discussion}

The average chemical composition of the steel used is given in Table 1. The total solid content of the cane molasses used is shown in Table 2. The specific heat capacity of the cane molasses used was determined to be $2162.48 \mathrm{JKg}^{-1} \mathrm{~K}^{-1}$. The physical and thermal properties of water and engine oil used is shown in Tables 3 and 4, respectively.

Table 1. Chemical composition of the as-received high carbon steel

\begin{tabular}{llllllllll}
\hline Element & C & Si & Mn & P & S & Cr & Mo & Ni & Sn \\
\hline Content(\%) & 0.61 & 0.254 & 0.754 & 0.0132 & 0.0172 & 0.108 & 0.0278 & 0.130 & 0.0054 \\
\hline & As & $\mathbf{C a}$ & $\mathbf{B}$ & $\mathbf{P b}$ & Sb & Al & Co & Cu & Fe \\
\cline { 2 - 10 } & 0.0233 & 0.0016 & 0.0010 & 0.0109 & 0.0130 & 0.0103 & 0.0153 & 0.196 & balance
\end{tabular}

Table 2. Total solid content of the cane molasses used

\begin{tabular}{lccccc}
\hline \multirow{2}{*}{ Molasses } & \multicolumn{3}{c}{ Constituents (\%) } & Viscosity(cp) & Brix No. \\
\cline { 2 - 4 } & $\begin{array}{c}\text { Sugar } \\
\text { content }\end{array}$ & $\begin{array}{c}\text { Water } \\
\text { content }\end{array}$ & $\begin{array}{c}\text { Non-sugar } \\
\text { materials }\end{array}$ & & \\
\hline $\begin{array}{l}{ }^{*} \text { Raw } \\
\text { molasses }\end{array}$ & 34 & 26 & 40 & 1041 & $\mathbf{7 4}$ \\
\hline $\begin{array}{l}\text { Prepared } \\
\text { molasses }\end{array}$ & $\mathbf{2 8}$ & $\mathbf{3 9}$ & $\mathbf{3 3}$ & $\mathbf{4 0}$ & $\mathbf{7 4}$ \\
\hline
\end{tabular}

( ${ }^{*}$ Source: Savannah Sugar Company, Yola) 
Table 3. Viscosity, specific gravity and specific heat capacity of water used

\begin{tabular}{|c|c|c|c|c|c|c|}
\hline \multicolumn{2}{|c|}{ Viscosity at $25^{\circ} \mathrm{C}$ (ср) } & \multicolumn{3}{|c|}{ Specific Gravity } & \multicolumn{2}{|c|}{ SHC $\left(\mathrm{Jkg}^{-1} \mathrm{~K}^{-1}\right)$} \\
\hline & 1 & & 1 & & & .80 \\
\hline $\begin{array}{l}\text { Viscosity } \\
\text { at } 25^{\circ} \mathrm{C} \\
\text { (cp) }\end{array}$ & $\begin{array}{l}\text { Viscosity } \\
\text { at } 100^{\circ} \mathrm{C} \\
\text { (cp) }\end{array}$ & $\begin{array}{l}\text { Viscosity } \\
\text { Index }\end{array}$ & $\begin{array}{l}\text { Flash } \\
\text { Point } \\
\left({ }^{\circ} \mathrm{C}\right)\end{array}$ & $\begin{array}{l}\text { Pour } \\
\text { Point } \\
\left({ }^{\circ} \mathrm{C}\right)\end{array}$ & $\begin{array}{l}\text { Specific } \\
\text { Gravity }\end{array}$ & $\begin{array}{c}\text { SHC (Jkg } \\
\left.{ }^{1} \mathbf{K}^{-1}\right)\end{array}$ \\
\hline 40 & 5.03 & 105 & 260 & 9 & 0.868 & 1740.21 \\
\hline
\end{tabular}

\section{Hardness}

Figure 1 shows the results obtained from hardness tests of the quenched and quenched-tempered samples in the various media.

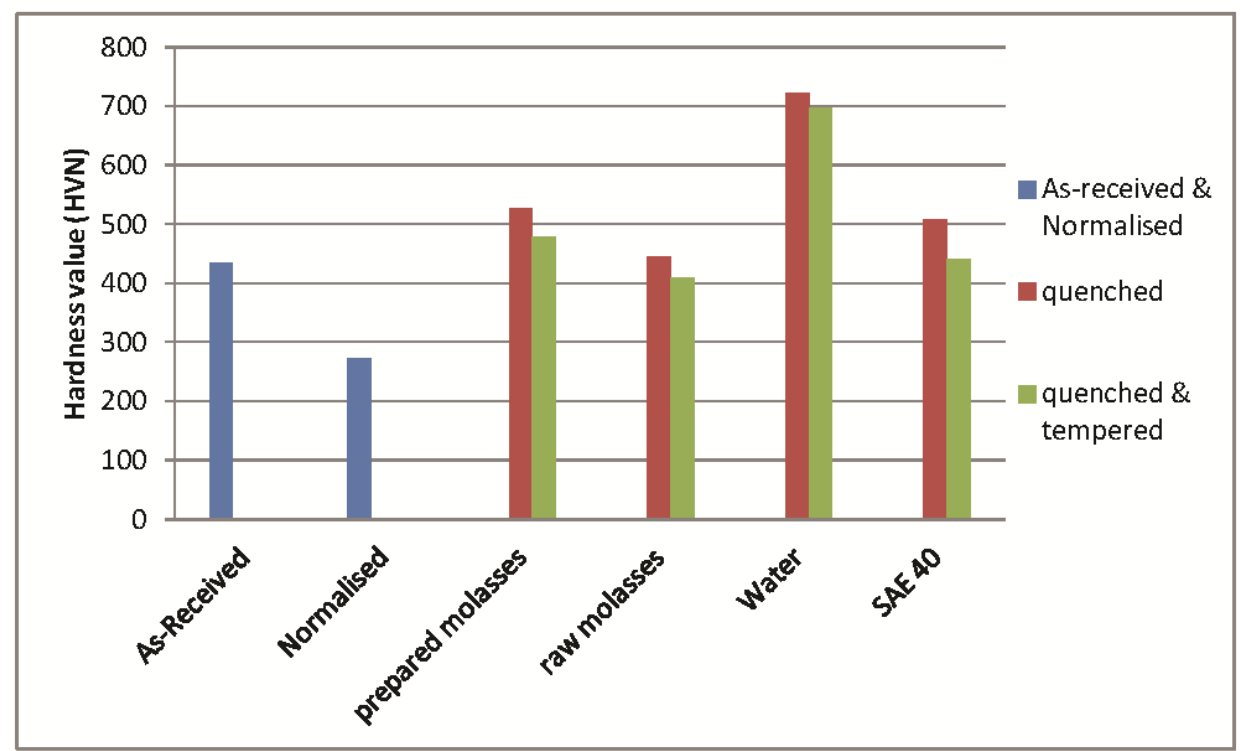

Fig. 1. Hardness profile of the high carbon steel samples quenched in different quenching media (in quenched and quenched-tempered conditions).

Figure 1 shows hardness results for samples quenched in different media (of different viscosities). The hardness values of $723 \mathrm{HVN}$ was obtained for the waterquenched sample as compared to $434 \mathrm{HVN}$ for the as-received sample. From the chart, it is clear that decrease in viscosity of the cane molasses caused increase in hardness value. Prepared molasses solution produced highest hardness of 525 HVN while raw molasses produced the least value of $444 \mathrm{HVN}$. The high hardness values obtained for sample quenched in prepared molasses solution could be explained by the fact that high density of dislocations were induced into the samples due to the higher cooling rate than 
those quenched in raw molasses solution. The trend showed by the hardness values in relation to the cooling rate of molasses solutions is similar to that observed in vegetable oils by Joseph et al. [7].

The hardness values of the quenched samples decreased slightly (Figure 1) after tempering. This could be attributed to the various microstructures obtained after tempering which revealed an increased in precipitation of cementite in fine supersaturated ferrite and lower bainite, due to decomposition of martensite and retained austenite [Figure 3(b, d), 4(b, d)]. These observations are in line with what Hassan et al. [17] established.

\section{Microstructures}

The microstructures of the as-received, annealed, normalized, quenched and quenched-tempered samples are shown in Figure 2 to 6 . The as-received structure of the test sample is shown in Figure 2(a); the structure consists of fine pearlite. The normalized structure of the high carbon steels used is shown in Figure 2(b); the structure reveals proeutectoid ferrite in pearlite matrix. The microstructures of the test samples quenched in water and engine oil are shown in Figure 3a and 3c, respectively. Water quenched samples showed high proportions of martensite (because of the high hardness value obtained from the sample). Oil quenched samples showed martensite proportion lower than that of water quenched sample. Both microstructures are associated with retained austenite. This is in line with the findings of Vivek et al. [18].

The microstructures of the samples quenched in the prepared molasses solutions and raw molasses are shown in Figure 4. All the microstructures of the samples quenched revealed the formation of martensite and retained austenite in varying proportions. The microstructures of samples quenched in prepared molasses solutions showed more of the austenite transforming to martensite compared to those quenched in raw molasses solutions and this might have accounted for the high hardness induced in the samples. This is in agreement with what was reported by Balogun [11].

The SEM images (Figure 5 and 6) showed that the martensite lath got coarser with increase in viscosity of molasses solutions. The reason could be attributed to fact that the cooling rate decreased as the viscosity was increased. This trend explains clearly the high hardness obtained for samples quenched in the prepared molasses solution. The structure of the quenched and tempered samples showed an increased in precipitation of cementite in fine supersaturated ferrite and lower bainite due to the decomposition of martensite and retained austenite [Figure 3(b, d), 4(b, d)]. The decomposition might have accounted for the reduction in hardness and strength after tempering. The observations are in line with what is obtained in the literature [17]. 


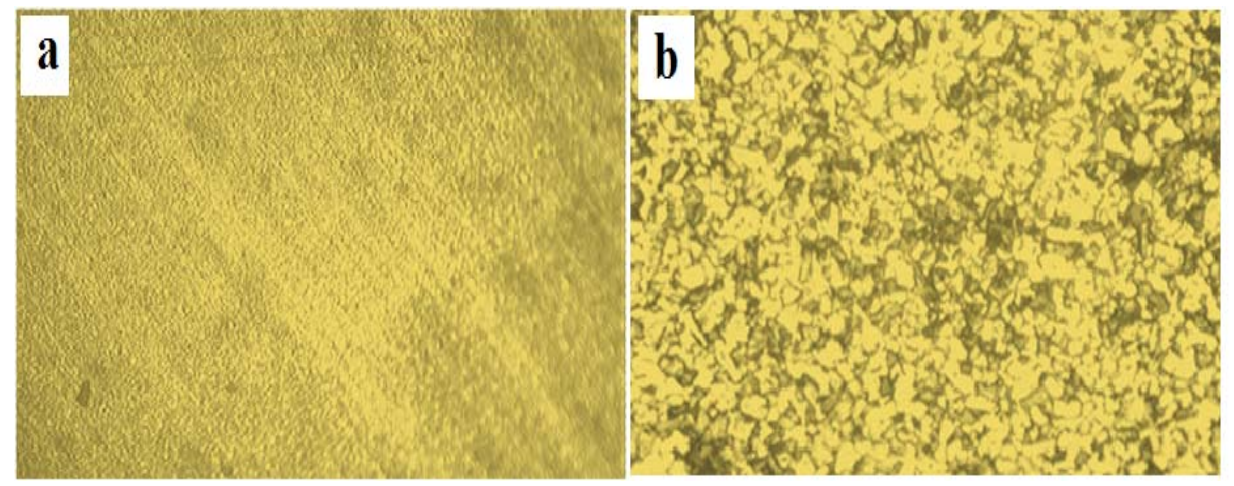

Fig. 2. Optical micrograph of high carbon steel. (a) as-received; the structure consists of fine pearlite; (b) after normalizing; showing regions of ferrite (white) and pearlite (black) structure. 2\% Nital etch. (x100)

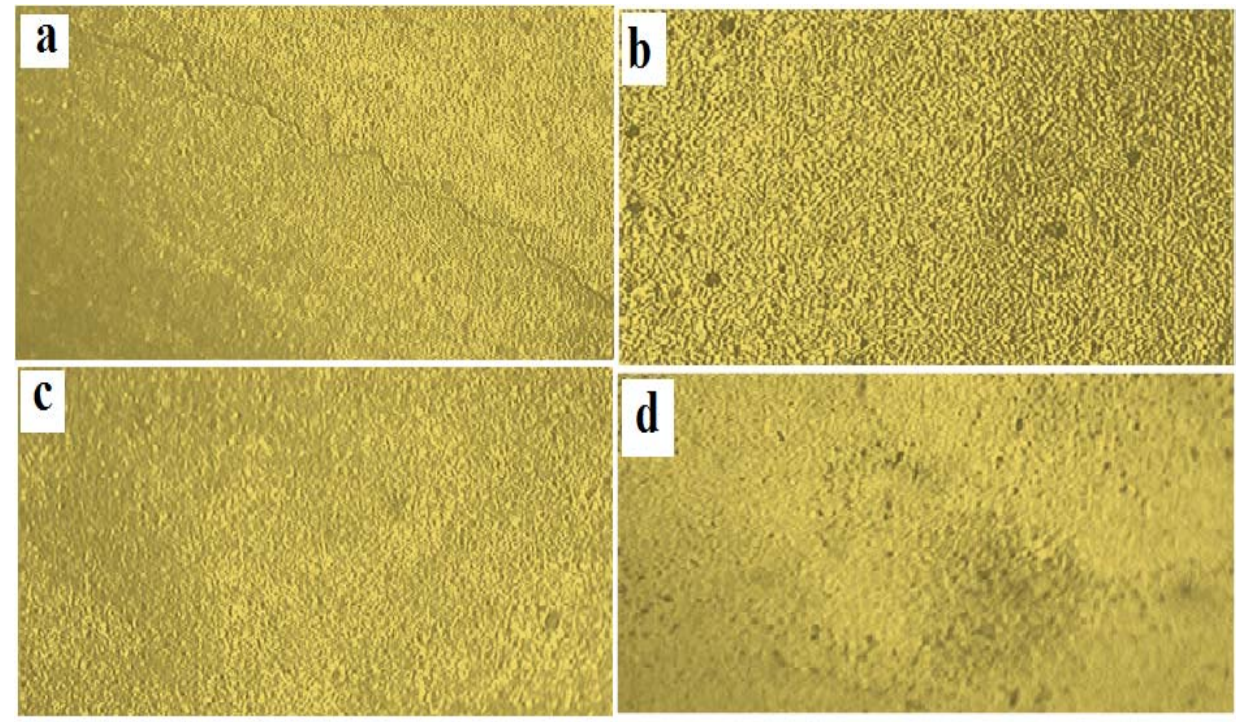

Fig. 3. Optical micrograph of the high carbon steel quenched. (a) in water; a structure of martensite (dark) and retained austenite (light-colored areas), with crack due to thermal and transformational stress; (b) in water and tempered at $350^{\circ} \mathrm{C}$; the structure consists of tempered martensite; (c) in SAE 40 Engine oil; the structure of martensite (dark) and retained austenite (light-colored areas); (d) in SAE 40 engine oil and tempered at $350^{\circ} \mathrm{C}$; the structure consists of tempered martensite. $2 \%$ Nital etch. $(x 100)$ 

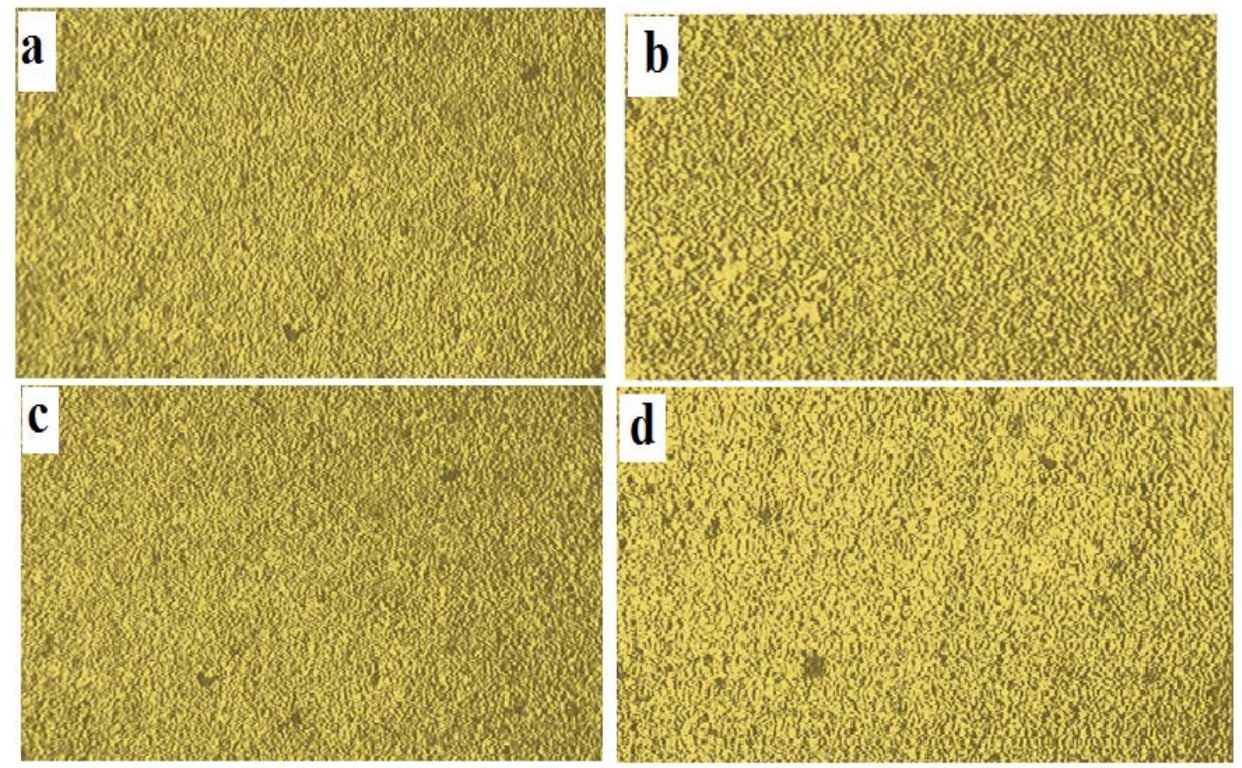

Fig. 4. Optical micrograph of the high carbon steel quenched. (a) in prepared molasses solution; a structure of martensite (dark) and retained austenite (light-colored areas);

(b) in prepared molasses solution and tempered at $350^{\circ} \mathrm{C}$; the structure consists of

tempered martensite; (c) in raw molasses; the structure of martensite (dark) and retained austenite (light-colored areas) (d) in raw molasses and tempered at $350^{\circ} \mathrm{C}$; the structure consists of tempered martensite. $2 \%$ Nital etch. (x100)
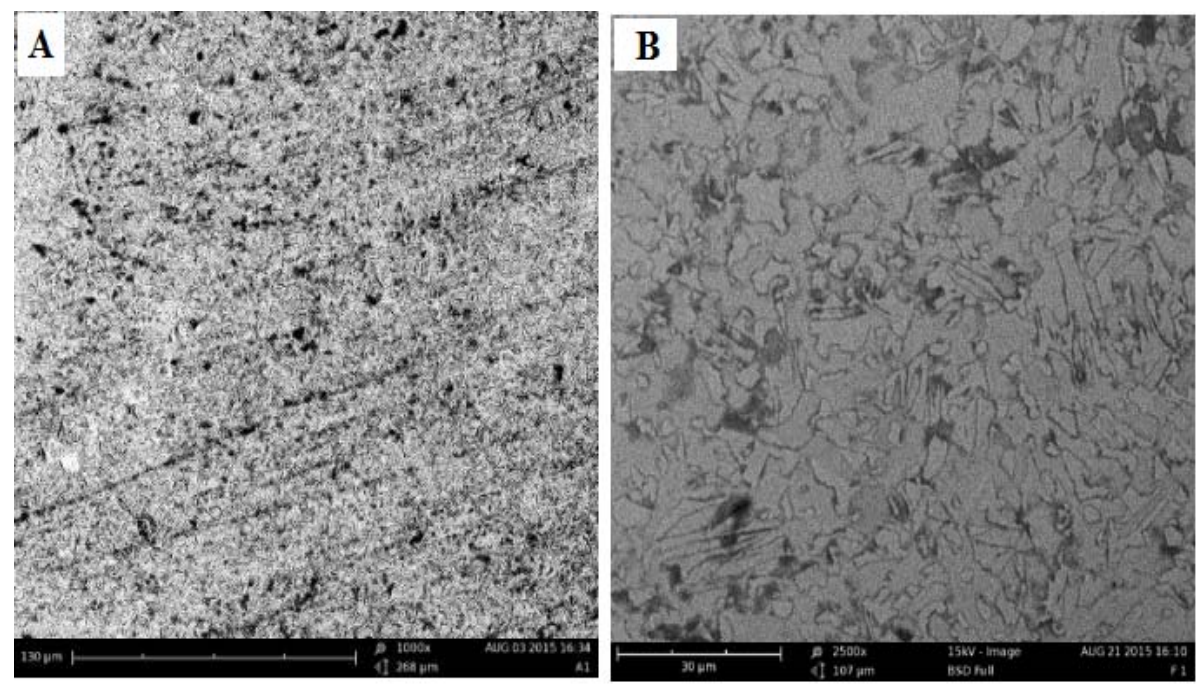

Fig. 5. SEM micrograph of high carbon steel quenched (A) in water, (B) in SAE 40 Engine oil; the structure of martensite (dark) and retained austenite (light-colored areas). 

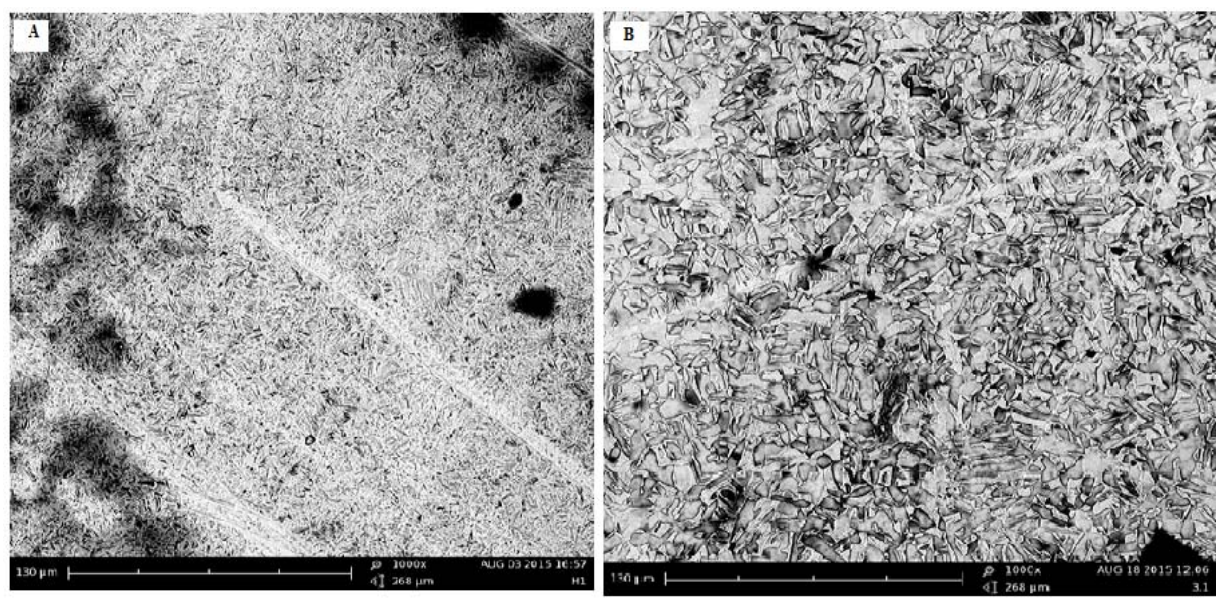

Fig. 6. SEM micrograph of high carbon steel quenched (A) in prepared molasses solution; (B) in raw molasses; the structure of martensite (dark) and retained austenite (light-colored areas).

Cooling rate curves

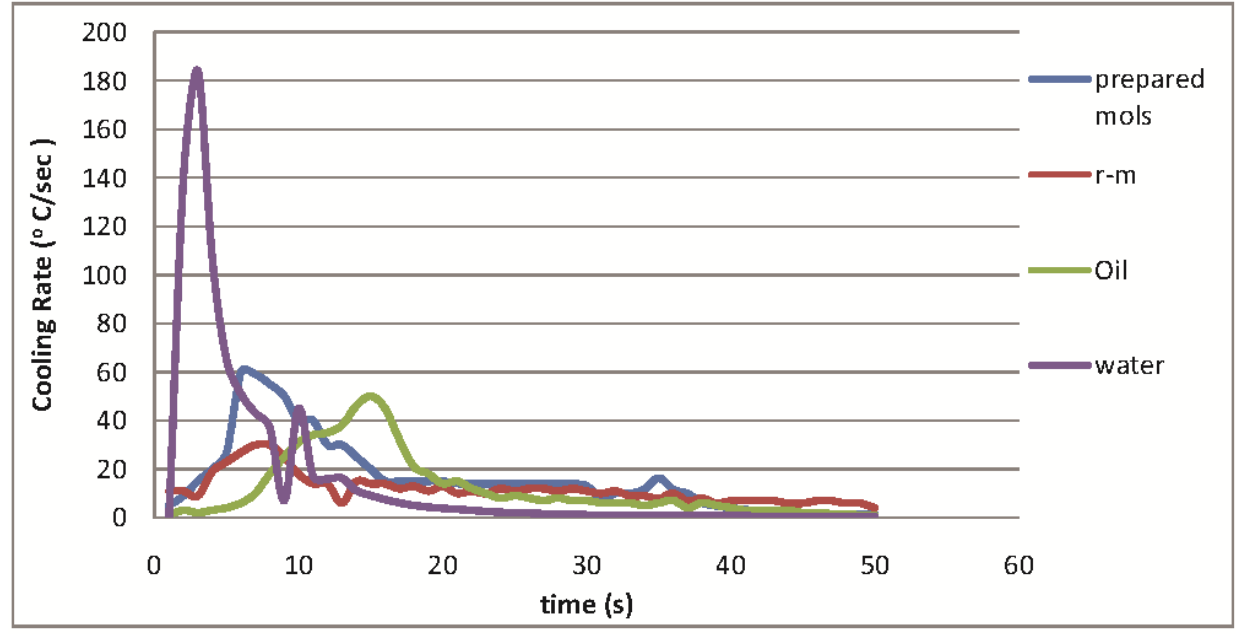

Fig. 7. Cooling rate curves of the quenching media, using a high carbon steel probe.

Note: prepared mols and r-m stand for prepared molasses and raw molasses respectively.

Figure 7 shows the cooling rate curves of the various quenching media used. The assumption used was that the temperature of the medium remained constant throughout the cooling operation. Water has shown the highest cooling rate of $184^{\circ} \mathrm{C} / \mathrm{sec}$ at the third second after quenching. The prepared molasses solution has shown higher cooling rate of the two molasses, having the highest cooling rate of $60^{\circ} \mathrm{C} / \mathrm{sec}$ at the sixth second. The raw molasses has its maximum cooling rate of $30^{\circ} \mathrm{C} / \mathrm{sec}$ at both seventh and eighth 
seconds. However SAE 40 engine oil has attained its maximum cooling rate of $50^{\circ} \mathrm{C} / \mathrm{sec}$ at the fifteenth second after quenching. The highest cooling rate of $60^{\circ} \mathrm{C} / \mathrm{sec}$ attained by the prepared molasses at the sixth second could be explained by the fact that as the viscosity of molasses decreases the heat extraction ability increases. This is in agreement with what was established by saska [15].

\section{Conclusions}

Potential of cane molasses as quenching medium in the hardening process of high carbon steel has been assessed using microstructure and hardness profile. Based on the results obtained, the following conclusions were drawn;

- The optical and SEM micrograph showed that the martensite lath got coarser with increase in viscosity of molasses solution. The reason could be attributed to fact that the cooling rate decreased as the viscosity was increased. This trend explains clearly the high hardness obtained for samples quenched in prepared molasses solution.

- $\quad$ High carbon steel could be hardened when quenched in cane molasses.

- $\quad$ The quench severities of the quenching media used depicts the following descending order: Water>prepared molasses solution>SAE 40 Oil> raw molasses.

- Molasses can harden high carbon steel without cracking the component in the same way as engine oil, hence, molasses could be a very good alternative to engine oil for use as quenching medium.

- $\quad$ Since molasses is cheaper and environmentally friendly compared to engine oil, molasses could be added to the list of existing quenching media.

\section{References}

[1] E. Keehan, Effect of microstructure on mechanical properties of high strength steel weld metals, Ph.D. thesis, Dept. of Physics, Chalmers University of Technology, Sweden, 2004.

[2] T.O Joshua, O.A Alao, R.T. Oluyori, Int. J. .Eng. Adv. Technol. 3 (2014), 121-127.

[3] G.E. Totten, Steel Heat Treating Metallurgy and Technologies, Taylor and Francis Group LLC, Oregon, USA, 2006.

[4] D.A. Fadare, T.G. Fadara, O.Y. Akanbi, J. Miner. Mater. Charact. Eng. 10 (2011) 299-308.

[5] G.Totten, M.T. Hans, S. Anton, Quenching and quenching technology-steel heat treatment. $\left(2^{\text {nd }} \mathrm{Ed}\right)$, Taylor and Francis Group LLC, Boca Raton, Florida, 2006.

[6] L. Olson, In: Proceedings 5. Physical Metallurgy: principle and practice, New Delhi: Prentice-Hall of India ltd. 1989.

[7] B.A. Joseph, A.K. Oladiran, M. Edeki, B.A. Michael, A.A Samuel, J. Miner. Mater. Charact. Eng. 10 (2015) 85-93

[8] C.C. Jensen, http://www.cjc.dk/index.php? m=p\&pid=212, 30 March 2016.

[9] B.O. Solomon, S.K. Layokun, T.O. Omobuwajo, Ife J. of Technol. 3 (1991) 25-29.

[10] V.C. Leo, Molasses general consideration, West Des Moines,: National Feed Ingredients Assoc. Iowa, 1983.

[11] S.O. Balogun, Potential of Cassava Liquid Extract as Quenching Medium for medium Carbon and Low alloy Steels, An M.Sc Thesis, Zaria: Department of Metallurgical and Material Engineering, Ahmadu Bello University, 2008. 
[12] T. Ause Evaluation of Hot Bitumen Bath as a Quenching Medium for Austempering of Steel and Ductile Cast Iron, A Ph.D Thesis, Zaria: Department of Metallurgical and Material Engineering, Ahmadu Bello University, 2007.

[13] S.B. Hassan, J.B Agboola, V.S. Aigbodiun, E.J. Williams, Metall. Mater. Eng. 5 (2010) 31-36.

[14] T.I. Muhammmad, Evaluation of Polymer Glycerol for Hardening Process in Steel and Cast Iron, Zaria: an M.Sc Seminar, Department of Metallurgical and Material Engineering, Ahmadu Bello University, 2007.

[15] M. Saska, Boiling rate, heat transfer and viscosity of technical sugarcane liquors, Louisiana, USA: Audubon Sugar Inst., Louisiana State University Ag Center, St Gabriel.

[16] O. R. Bodede, P.O. Ojo, O.R. Ayodele, A.F. Owa and O.B. Ajayi, J. Emerging Trends Eng. Appl. Sci. 3 (2011) 127-130.

[17] S.B Hassan, S.O. Balogun, V.S. Aigbodion, Metall. Mater. Eng. 4 (2009) 55-61.

[18] T. Vivek, P. Adarsh, M. Zuber, I.B. Chandrashekhar, Int. J. Innovative Res. Adv. Eng. 1 (2014), 46-49.

[19] ASTM "Standard Test Method for Determination of Cooling Characteristics of Quench Oils by Cooling Curve Analysis”, ASTM International, 100 Barr Harbor Drive, West Conshohocken, PA 19428-2959 USA, 2007.

[20] ASTM "Standard Test Method and definitions for mechanical testing of steel products”, ASTM International, 100 Barr Harbor Drive, West Conshohocken, PA 19428-2959 USA, 2007.

[21] W.D. Callister, Material Science and Engineering: An Introduction, John Wiley and Sons Inc., New York, 1997, 331-337.

[22] C. S. Ester, F. O. Luiz, E. T George, C. F. Lauralice, J. Pet. Sci. Res. 2 (2013), 4147. 